\title{
A GENERALIDADE DA LEI
}

\author{
Benjamim de Oliveira Filho \\ Professor Catedrático da Faculdade de \\ Direito de Niterói
}

1. O princípio da generalidade da lei. Teoria dominante.

2. Justificação da doutrina.

3. Os fatos: a diversidade do real.

4. O recuo estratégico: a noção da impessoalidade da lei.

5. O desbarato total da teoria: a decadência da conceituação clássica, de que deriva o princípio da generalidade da lei.

6. A lição de CARRÉ DE MALBERG.

7. Últimas apreciações.

8. A questão das leis formais e leis materiais.

9. A solução do problema no sistema jurídico do AQUINATE.

10. Conclusões.

1. Poucas teorias se nos apresentam ao espírito tão imponentes, como esta, da generalidade da lei, esforçando-se na tradição e no consenso pràticamente unânime dos expositores. Sua simplicidade e o íntimo, próprio logicismo, que encerra, seduzem e convencem. A lei é geral, segundo a doutrina, e não visa a casos singulares, o que decorre de sua própria natureza e, ao mesmo passo, representa um princípio de segurança, pois todos serão, assim, iguais perante a lei. A razão, a igualdade e a liberdade se acomodam a tal ensinamento, que traz consigo a consagração dos séculos e o apoio dos doutrinadores. 
PAPINIANO declara, no Digesto (I, 3, 1), que lex est commune praeceptum e ULPIANO, pouco adiante (I, 3, 8), esclarece: iura non in singulas personas, sed generaliter constituuntur.

Os filósofos, os escritores políticos e os juristas, em geral, seguem na mesma esteira.

Há um trecho célebre de ARISTÓTELES, sempre citado. Está na Política (Livro I, cap. 15, 1286 a, ed. bilíngüe de Julian Marias) e reza: "as leis só falam em têrmos universais e não estabelecem determinações para os casos que efetivamente ocorrem". Mas, na verdade, seria forçoso notar que ARISTÓTELES não cogita senão incidentemente do assunto. Considera, especialmente, naquele ponto, a questão de saber se é mais conveniente ser governado pelo melhor homem, ou pelas melhores leis. Alude, então, à generalidade da lei, apontando a opinião dos partidários da monarquia. Como se vê, não foi o tema versado ex professo, perdendo bastante, assim, em significação, o escólio do ESTAGIRITA.

De MONTESQUIEU alega-se, também, uma passagem no capítulo 16, do livro 29, de $O$ espírito das leis (Oeuvres complètes, ed. Pléiade, 1951, vol. II, pág. 877), de somenos importância para o caso. Lá estuda o famoso publicista a maneira como devem ser compostas as leis, afirmando: "é essencial que as palavras da lei despertem em todos os homens as mesmas idéias".

ROUSSEAU, no Contrato social (Livro II, cap. 6, ed. de 1772, Oeuvres, vol. II), trata abundantemente da matéria. A lei, segundo êle, é expressão da vontade geral. Ora, essa vontade geral não pode ser senão geral, porque emana de todos, compondo o celebrado "eu comum", e porque não se manifesta senão sôbre assuntos gerais, assuntos comuns, que a todos dizem respeito, isto é, à inteira comunidade, ao povo, formando o corpo político. Assim, esclarece ROUSSEAU (loc. cit.), a lei só considera "os homens constituídos em corpos e as ações em abstrato". Portanto, de sua origem, que é a vontade geral, tira a lei seu objeto e seu alcance, que não podem ser senão gerais. A lei reúne "a universalidade da vontade e a do objeto" (loc. cit.), ao passo que "a determinação do próprio soberano, sôbre um objeto particular, não é lei, mas de- 
geral é o princípio que deriva da natureza das coisas e funda-se na razão" (op. cit., pg. 13). O próprio MONTESQUIEU proclama que "a lei, em geral, é a razão humana enquanto governa todos os povos da terra" (L'Esprit des lois, I, 3, ed. cit.). O prestígio fabuloso da razão humana ainda se engrandece da circunstância de que, no caso, não se trata, apenas, da inteligência de alguns, de uma elite particularmente sábia e esclarecida, mas, como frisa o citado BURDEAU (pgs. 13 e 14), da "participação universal dos homens num julgamento infalível acêrca do interêsse comum". A lei é a expressão da vontade geral e, segundo a idéia corrente, "uma nação deve fazer suas próprias leis, porque é composta de sêres inteligentes, a quem Deus concedeu uma razão para julgar do que lhe mais convém" (pg. 14).

3. Tal é a doutrina da generalidade da lei, em sua origem e em seu fundamento.

Consideremos, porém, as conseqüências, os resultados de sua aplicação, os fatos como se patenteam, e já repontam as dificuldades. Essa decantada generalidade não atinge a universalidade, pròpriamente, como tudo faria prever. A diversidade do real exige que a lei distinga entre casos diversos. $O$ conceito de uma generalidade absoluta da lei, implicando sua universalidade, isto é, sua eventual aplicabilidade a todos, não condiz com as condições positivas de nossas atuais sociedades, "fundadas, tôdas, sôbre uma concepção hierárquica, admitindo, tôdas, o arbítrio do legislador", na exata observação de HENRIQUE DUPEYROUX (Mélanges Carré de Malberg, 1933, pgs. 144 e 145).

Com efeito, as legislações modernas tiveram que se acomodar à inelutabilidade dos fatos, atendendo àquela diversidade do real. Exemplo típico da variedade dessas relações é o trabalho humano. O trabalho não é acidente na vida do homem; é função característica, indeclinável, por meio da qual êle coopera, com a parcela de sua atividade, na instauração do bem comum. É a regra, é um dever do homem. SÃO PAULO dizia que o que não trabalha não tem direito a comer (2. Epistola aos Tessalonicenses, II, cap. 3, 10). Assim, todos trabalham ou deveriam trabalhar. E atividade comum e geral, que se prestaria, portanto, a legislação unifor- 
me, aplicando-se a todos. Por ser obrigação geral, deveria ser regulada por lei geral, o que se não verifica. A atividade do trabalhador e as relações jurídicas, que dela decorrem, são regidas por legislação especial. A do funcionário público é regulada por outras leis, prevalecendo o regime estatutário. E esta categoria não pode ser tomada em conjunto, como também, aliás, a do trabalhador, em que se notam outras tantas discriminações. No servidor público, há que distinguir a incidência de várias legislações particulares, atendendo a circunstâncias peculiares. O militar tem seu Código próprio; o juiz, o professor, o diplomata, cada qual é regido por leis particulares, especiais, por vêzes esparsas, mas típicas, ponderando aquelas circunstâncias peculiares a cada espécie de trabalho, ou função. As profissões liberais têm suas leis próprias, também, e assim por diante, verificando-se, cada vez mais acentuada, a tendência para a especialização. Onde, pois, a universalidade, a generalidade da lei?

4. O caso é que, mostra DUPEYROUX (op. cit., pg. 150), sob a pressão dos acontecimentos, se operou um recuo estratégico para uma noção mais maleável, menos rígida, para uma noção relativa de generalidade, constituindo, pròpriamente, uma noção negativa dessa generalidade (pg. 151). A lei é geral, afirma-se, quando determina sem consideração de pessoa, ainda que vise expressamente a certa categoria de pessoas ou de fatos. A generalidade, ou universalidade, transmuta-se, assim, em impessoalidade, critério menos duvidoso, mais fàcilmente reconhecível. Contudo, generalidade e impessoalidade estão longe de ser expressões sinonímicas, pois os critérios não se sobrepõem exatamente um ao outro, existindo, tão sòmente, por vêzes, coincidência entre os dois (pg. 151).

Sob outro aspecto, a aceitação dêsse critério faz desaparecer o princípio de garantia, ou segurança, que era o fundamento ideológico da teoria da generalidade. Fica, assim, singularmente facilitada a tarefa do legislador quando, visando a caso, a pessoa, a situação particular, reveste a determinação legal de aparente caráter de generalidade. O exemplo histórico de Herodes, prescrevendo o extermínio de tôdas as crianças, buscando um fim implícito, não especificado, nem personalizado, pode ser repetido a cada passo (pg. 153).

Então, tudo passaria a se reduzir a simples artifício, e a 
tênue cortina, que separa os atos legislativos impessoais dos que o não são, poderá ser fàcilmente descerrada pelo poder público, como, na realidade e com muita procedência, por vêzes, acontece, e às escâncaras, sem emprêgo de qualquer subterfúgio. São inúmeras as leis estatuindo favores, pensões, honrarias, estabelecendo, em suma, privilégios ou exceções, justificadas ou não, ao arrepio das prescrições do direito comum.

Destarte, o reino abstrato da lei transmuda-se, por caminhos singelamente encurtáveis, no reino do legislador, a cujo poder de arbítrio, no direito positivo, nada haverá de se lhe opor, senão uma regra fundamental e primeira, a norma constitucional, aliás, também pelo homem elaborada, fruto do legislador e susceptível, ainda, de modificações, uma vez cumpridas determinadas formalidades. Como afirma egrègiamente CARRÉ DE MALBERG (Teoria general del Estado, trad. espan., 1948, pgs. 284 e 285, n. ${ }^{0} 98$ ), "em matéria de decisões individuais, o legislador não se encontra limitado senão por seus próprios sentimentos de eqüidade e por considerações de oportunidade política". Em conseqüência, o legislador, ardilosa ou francamente, poderá editar leis particulares, concernentes a casos particulares e, como nota DUPEYROUX (pg. 157), "uma autoridade arbitrária e de espírito despótico não se furtará a essas práticas, como, também uma autoridade, compenetrada do espírito de justiça e preocupada de legislar com eqüidade, não o deixará, igualmente, de fazer".

Resumindo, eis o testemunho inelutável dos fatos. A generalidade da lei não é, nem pode ser absoluta. Ela não é universal. Nem o poderia ser, sem grave dano e, ainda, sem injustiça ou iniqüidade. Impessoalidade, então, a modo de generalidade negativa, estatuindo sem personificar? Muitas vêzes, quase sempre, talvez, quando caiba, segundo as circunstâncias. Porque há medidas que hão de ser tomadas com relação a casos particulares, onde serão resolvidos interêsses particulares. A medida não é geral, visando, antes, a determinado caso. A encampação de uma emprêsa, de uma companhia; a federalização de uma Faculdade de ensino superior. São casos particularíssimos, em que estão em jôgo interêsses privados. Nada importa que a lei tenha em mira 
os altos interêsses da coletividade. De fato, na hipótese, a lei abandona a generalidade para resolver situações particulares e individuais e, portanto, interêsses particulares. Por trás dessas entidades, há pessoas, interêsses personalíssimos. A lei não os regula de modo geral, mas particularíssimo, em obséquio a especiais circunstâncias. Poderia, no exemplo citado, estatuir por via geral, federalizando tôdas as Faculdades de ensino superior, como poderia federalizar, apenas, tôdas as Faculdades de direito, ou tôdas as Faculdades de medicina, ou tôdas as politécnicas, como igualmente pode federalizar, sòmente, determinada Faculdade. Não é o princípio da generalidade ou o da impessoabilidade da lei que a impediria de o fazer. E, além dêsses casos particulares, especiais, que hão de ser regulados, aquelas disposições legais personalíssimas, a que já nos referimos: pensões, honrarias, dispensas, privilégios ou exceções, em suma, atendendo, não poucas vêzes, a reclamos imperiosos de justiça distributiva.

Nem se deverá, com efeito, supor que tais determinações particulares constituam, em si e em princípio, desacêrto do legislador, ou atentado à finalidade do bem comum, característico essencial da lei. Com sua penetração costumeira, já observara SANTO TOMÁS (1a. 2ae., qu. 90, art. 2. ad lum.) : "O preceito comporta uma aplicação da lei aos atos que são por ela regulados. A regulamentação em vista do bem comum, que é o característico da lei, é aplicável a fins privados. $\mathrm{E}$, neste sentido, são editados preceitos concernentes a certos fatos particulares". Isto porque, explica o DOUTOR ANGÉLICO (qu. 90, art. 2. ad 2um.): "as ações (operationes, isto é, o operar humano) não se realizam senão por meio de fatos particulares..." E êsses fatos particulares não podem deixar de ser objeto de regulamentação legal, por meio, quiçá, de determinações especiais, segundo o exijam as condições e circunstâncias oriundas de sua própria especificidade.

5. A lição dos fatos, portanto, não corrobora a célebre doutrina. $\mathrm{E}$ há mais o seguinte, que pode ser exposto teòricamente, mas também é lição dos fatos, decorrendo da observação da realidade histórica. BURDEAU, em seu mencionado trabalho, mostra a decadência daquela antiga conceituação de lei, majestosa e imponente, que se tornou clássica e de que derivou o princípio de sua generalidade necessária. 
autor considera e comenta o que passa na França e no direito francês. Mas, entre nós, o quadro não se modifica. Mutatis mutandis, o panorama é o mesmo. Aqui e alhures.

Vejamos, pois, como se processa e de que provém a decadência apontada.

Em primeiro lugar, não se acredita mais nas idéias (op. cit., pgs. 29 e segs.) e a tradicional noção de lei sempre foi, como vimos, eminentemente ideológica. E não só a referida concepção revolucionária e racionalista. SANTO TOMÁS, em sua definição de lei, fala em ordinatio rationis (1a. 2ae., qu. 90, art. 4, ad resp.). A nota, no sistema tomista, é posta na razão. Êsse princípio, hoje, foi relegado a oblívio. O prestígio das idéias, o intelectualismo, já fez seu tempo. Pretende-se outra coisa e, no terreno da filosofia jurídica, campeia a noção oposta de um voluntarismo sem peias.

Outro sintoma da época é o desprêzo crescente pelo legislador (pgs. 31 e segs.). Não se lhes dá a menor importância a êsses chamados representantes do povo, que são os legisladores. Dêles, nada se espera. Nêles, não se crê, nem, portanto, em sua obra, que é a lei. A consideração pública e o respeito totalmente desapareceram.

Mas a lei não está só desmoralizada pelo aviltamento de seus autores. Seu descrédito provém, igualmente, dos estudos sociológicos, de caráter avalorativo, tendendo a inculcar que ela não passa de mera superestrutura, de decorrência inevitável de um conjunto de circunstâncias. A lei não é mais senão um documento (op. cit., pgs. 37 e segs.).

Sob outro aspecto, a lei também se apouca na consideração de sua caducidade e de sua insuficiência, ostentada nos fatos e proclamada pelos juristas. A todo o transe, procurase demonstrar sua esterilidade, estabelecendo-se o cômputo de suas lacunas (pgs. 39 e 40).

Finalmente, conseqüência fatal de tudo, o Estado, encarnando o poder público, não se impõe mais ao respeito, como autoridade política; é uma simples metáfora, designando os governantes (pgs. 41 e 42).

Assim, conclui gravemente BURDEAU, a lei não é mais geral, nem abstrata, nem permanente (pg. 44). A lei passou 
a ser um processo de govêrno (pg. 47). Representa um conjunto de medidas particulares, visando ao proveito de cada grupo, que pleiteia um direito seu, próprio, consoante os próprios interêsses, sequela inevitável do primado reconhecido do econômico, implicando o estabelecimento de infinitas hierarquias entre os homens (pg. 44). A lei não é mais, também, um princípio. PORTALIS proclamava que a missão do legislador era a de "fixar, em largos apanhados, as máximas gerais do direito; a de estabelecer os princípios fecundos em conseqüências, sem descer ao pormenor das questões, que podem surgir em cada matéria" (Discours préliminaire, pg. 4, in Motifs et discours prononcés lors de la publication du Code Civil, Paris, Firmin Didot, 1841, vol. 1. ${ }^{\circ}$ ). A lei deixou de ser um princípio, para ser apenas uma solução (pg. 50), inferindo-se daí seu caráter francamente político e êsse voluntarismo exacerbado, prevalente, em que o legislador é dono da lei (pg. 51). Os dois impressionantes livros de RIPERT, Le régime démocratique et le droit civil moderne (1936) e o último, Les forces créatrices du droit (1955), proporcionariam abundantes elementos sôbre êstes temas.

6. Deixamos para o fim, encarecendo sua importância, as ponderações de CARRÉ DE MALBERG, o grande campeão, pioneiro, nesse combate à doutrina metafísica da generalidade da lei.

Rebatendo a teoria da generalidade necessária da lei, CARRE DE MALBERG sustenta resumidamente o seguinte.

Os partidários dessa tese afirmam que a generalidade da lei é uma garantia para o cidadão. A generalidade estabeleceria o primado da lei, num regime de igual proteção a todos. Ora, argumenta CARRÉ DE MALBERG, para alcançar seus fins de proteção, não basta que a lei seja geral. É mister, antes de tudo, seja dotada de fôrça predominante, vinculando os governantes, ou, com maior precisão, vinculando a autoridade administrativa. É neste elemento formal que repousa vèramente a garantia do princípio da legalidade (Teoria cit. n. 0 98, pg. 280).

Grande número de leis, é certo, formulam regras gerais, susceptíveis de aplicação a um conjunto de pessoas e de casos. Isto se explica porque as relações sociais apresentam, 
muitas vêzes, caráter de constância. Essa generalidade habitual da lei não lhe é, porém, indispensável ou necessária. A lei, por vêzes, tem por objeto um caso isolado, momentâneo ou atual. E neste sentido, sobejam os exemplos (n. ${ }^{\circ} 98$, pgs. 280-282).

Assim, não é verdade que as regras gerais constituam matéria própria e privativa da lei. Não só esta prescreve determinações gerais. Há um poder de regulamentação, também geral, que pertence à autoridade administrativa. Não se poderá, então, dizer que a regulamentação geral compete à atividade legislativa, enquanto que a autoridade administrativa procederia por meio de decisões particulares. Tal o contraste que se pretende estabelecer: a lei regula por meio de disposições gerais, ao passo que a autoridade administrativa atuaria por via de determinações particulares. A generalidade seria o privilégio e o característico da lei. Ora, na realidade, o que existe é outra coisa. Os poderes, concedidos à administração, para dar execução à lei, estão subordinados à própria lei. Assim, qualquer medida, embora particular, dessa autoridade, que ultrapasse os extremos traçados na lei, excede os limites da função administrativa, exigindo a intervenção do poder legiferante (n. ${ }^{0}$ 98, pgs. 282 e 283).

Alegam, por fim, os defensores da teoria de generalidade, que o legislador está adstrito às leis existentes e, destarte, não deverá, nem fôra conveniente derrogar os princípios gerais, estatuindo normas para casos particulares. A verdade verdadeira é que o legislador tem poderes para fazê-lo, colocada a questão no terreno estritamente jurídico. Não vale alegar o princípio da igualdade perante a lei. Tal princípio não passa de mera diretiva, de conselho prático, de "recomendação política" (n. ${ }^{\circ}$ 98, pg. 284). Na realidade, convém repeti-lo, "em matéria de decisões individuais, o legislador não se encontra limitado senão por seus próprios sentimento de eqüidade e por considerações de oportunidade política" (n. ${ }^{0}$ 98, pgs. 284 e 285).

7. Eis o que resta da famosa teoria da generalidade da lei. Os fatos certamente não a confirmam. O que vemos é uma legislação oportunista, submissa a injunções de momento, sem princípios orientadores, nem finalidade, satisfazendo a interêsses, cedendo à pressão política e econômica dos mais 
fortes. Nada disto se assemelha à concepção majestática da lei, preconizada, a sua impessoalidade sagrada, que não é mais senão imparcialidade e justiça, ao senso da coisa pública, à plena consciência da responsabilidade moral, apanágio do legislador, daqueles, em suma, que têm a seu cargo a segurança da ordem e a instauração do bem comum.

E não é só. Não são apenas os fatos, que desmentem a teoria. Seus próprios fundamentos são vacilantes e frágeis. Tais como são apresentadós, não convencem, nem procedem. O principal dêles, o que faz derivar do sistema da generalidade a garantia da proteção legal, é puramente fantasioso e perfeitamente inócuo. O regime da legalidade, com sua proteção eficaz, decorre da fôrça vinculante de que seja armado o preceito jurídico. É preciso que êle se imponha a governantes e governados. É mister seja o sistema jurídico vèramente obrigatório, e se constitua, para todos, num dever. $\mathrm{E}$ todos os deveres, escreve KANT, na Introdução de seus Princípios metafísicos do direito (trad. franc. de J. Tissot, 1937, pg. 16), "todos os deveres, só por serem deveres, pertencem à ética". Não é por meio de fórmulas, nem de sistemas vãos, que se implanta a genuina imponência da lei. A lei, a normatividade jurídica, o regime perfeito da legalidade, o lídimo rule of law, só se obtém fazendo apêlo a outros princípios transcendentes, que tornem a norma realmente obrigatória, quer dizer, obrigatória em consciência. Só o fundamento moral da norma jurídica lhe emprestará êsse caráter de imponência, de véra obrigatoriedade em consciência.

A doutrina da generalidade necessária da lei é, em conseqüência, uma doutrina irreal e caduca, oriunda de princípios metafísicos, diretamente filiados às fábulas de ROUSSEAU, cujos maléficos efeitos inexplicàvelmente perduram.

8. A distinção entre leis materiais e leis formais não aproveita ao assunto, nem resolve o problema debatido.

Acontece, porém, que alguns autores, escudados em noções imperfeitas, elidem a questão da generalidade necessária da lei, alegando que as disposições legais, concernentes a determinados fatos ou a determinadas situações individuais, não constituem verdadeiras leis, isto é, leis materiais, não são pròpriamente atos legislativos, mas simples leis formais, atos 
de govêrno ou de administração, praticados pelo Parlamento, como dizem J. BARTHÉLEMY e P. DUEZ (Traité de droit constitutionnel, 1933, pg. 728), ou, segundo DUGUIT (Manuel, pg. 93), meros atos administrativos ou jurisdicionais.

A propósito, escreve peremptòriamente DUGUIT ( $M a-$ nuel, pg. 93): "A disposição por via geral e abstrata é lei no sentido material. A disposição por via individual e concreta não é lei no sentido material; é lei no sentido formal, se emana do órgão legislativo. Sob o aspecto material, será, segundo as circunstâncias, ato administrativo ou ato jurisdicional". Êste escólio de DUGUIT é o mesmo que se encontra, palavra por palavra, no Traité (vol. 2. ${ }^{\circ}, 2^{\text {a }}$ ed., 1923, § 15, pg. 146), onde o sábio Decano, como sempre, exaure o assunto, com o apoio das melhores fontes de informação (Traité, vol. 2. ${ }^{\circ}$, pgs. 140 e segs.).

$\mathrm{E}$ os exemplos tirados a lume, no ponto, pelos mencionados ilustres tratadistas esclarecem-lhes nìtidamente a posição assumida: a reintegração nos quadros do Exército francês e a respectiva promoção do capitão Dreyfus e do coronel Picquart; a pensão concedida à viúva do marechal Joffre (loc. cit.).

Ora, essa doutrina, discriminando entre leis materiais e leis formais, nos vem do direito e dos expositores tudescos. $\mathrm{E}$ a diferença por êles estabelecida, entre as duas, assenta em critério diverso. Partem êsses autores do princípio de que tôda regra, que cria direitos, é matéria de lei. Nestas condições, lei material nada mais é senão uma regra de direito. É o que sustenta PAULO LABAND (Le droit public de l'empire allemand, ed. franc., Paris, Girard et Brière, 1901, vol. 2.0, pg. 261): "Lei, no sentido material do têrmo, é, por definição, o estabelecimento de uma regra de direito". E, mais adiante, conceituando a regra de direito, diz que ela consiste ou tem por fim circunscrever os direitos e deveres mútuos dos indivíduos, ou, textualmente: "O direito consiste em limitar os direitos e deveres mútuos dos indivíduos" (loc. cit., pg. 518). Nada importa se refira a lei a número ilimitado de casos ou, tão sòmente, a caso particular ou isolado. É o que expressamente afirma LABAND, completando a definição de lei material, acima apontada: "o que não implica necessàriamente seja uma regra geral, aplicável a número indeterminado de 
casos semelhantes" (loc. cit., pg. 261). E, declaradamente, logo depois (pgs. 262-263), reafirma seu pensamento, ilustrando a assertiva com exemplos característicos: "A noção de lei não exclui a possibilidade da existência de lei, estabelecendo uma regra de direito aplicável a um fato único, ou destinada a regular jurìdicamente uma relação jurídica individual" (loc. cit., pg. 262).

JORGE JELLINEK, outro grande propugnador desta tese, que ficalizamos, não é menos explícito e categórico. Em sua Teoria geral do Estado (ed. espan., Buenos Aires, 1954, pg. 462), estudando as "funções materiais do Estado, a saber: legislação, jurisdição e administração", assim conceitua a função legislativa: "A legislação estabelece uma norma jurídica abstrata, regulando uma pluralidade de casos, ou um fato individual" (loc. cit.).

CARRÉ DE MALBERG, que considera aprofundadamente êste assunto, dedicando-lhe amplo desenvolvimento, não discrepa dessa compreensão da teoria dos escritores alemães. Mostra que a doutrina alemã pretende extremar, segundo seu direito constitucional positivo, o campo da competência legislativa e o da competência administrativa (op. cit., pg. 285). E, comentando, a seguir, uma passagem de JELLINEK, esclarece que, segundo a interpretação dada ao direito positivo pela referida doutrina, "qualquer decisão, posto seja tomada a título particular, desde que modifique a ordem jurídica vigente, torna necessária uma lei e, pois, neste sentido, é matéria de lei. Nisto se funda JELLINEK para afirmar que tôda disposição, criando direito individual novo, é lei material, ainda quando apenas se refira a uma ou várias pessoas determinadas" (op. cit., pg. 287).

Portanto, segundo a teoria, lei material é a que constitui, a que contém uma regra de direito; a que delimita o campo dos direitos e deveres mútuos dos indivíduos; a que cria direitos ou estabelece deveres; a que modifica a ordem jurídica vigente. Tal a matéria própria da lei. Em conseqüência, o que qualifica a lei formal é a ausência dêsse conteúdo, dessa finalidade, dessa matéria, em suma, posto seja ela emanada dos órgãos legislativos e revestida, portanto, dos característicos formais da lei. 
Nesta ordem de idéias, eis um lance decisivo de LABAND, fixando o contraste entre lei material, lei - regra de direito e simples "lei administrativa", lei meramente formal, sem conteúdo jurídico, estranha ao direito: "As regras que não ultrapassam as raias da própria administração, que, em qualquer sentido, não impõem limitações ou não conferem poderes a um indivíduo alheio a essa administração, nada lhe concedem e nada lhe tiram, nada lhe prescrevem e nada lhe proíbem, não são disposições jurídicas" (loc. cit. pg. 519).

Êste é o sentir de todos os autores de melhor lição, desde o clássico e insuperável FILOMUSI GUELFI (Enciclopedia giuridica, 1910, pgs. 77 e 79) até o moderno e abalizado DEL VECCHIO (op. cit., pgs. 222 e 223).

A lídima distinção entre lei material e lei formal não depende da generalidade ou da particularidade do mandamento; depende do conteúdo jurídico do preceito, decorre da circunstância de conter a disposição numa norma de direito, uma regra jurídica, ou de, tão sòmente, ao contrário, reunir os requisitos extrínsecos, os caracteres formais da lei, isto é, de, na ausência daquele conteúdo jurídico, ser, apenas, lei na forma.

Finalmente, essa discriminação, tal como é preconizada, entre leis materiais e leis formais, sôbre não resolver a debatida questão da generalidade essencial da lei, não se isenta, apreciada em si, de graves increpações.

A regra jurídica, a lei pròpriamente dita, não passaria, nessa conceituação, de mera norma de conduta individual, de mandamento, de ordem ou determinação, visando, exclusivamente, ao comportamento do cidadão, destinatário do preceito. Tornaríamos, assim, àquela concepção caduca, por incompleta, de norma agendi, individualista e arbitrária. Já SANTO TOMÁS, em sua definição de lei, fala em ordinatio rationis, inculcando o caráter incomutável de organização, inseparável do conceito de lei. Ela não é, apenas, uma ordem, um mandamento, uma determinação de fazer ou não fazer, nem se dirige ao indivíduo, considerado como tal e concebido em abstrato. A lei ordena no sentido de estabelecer ordem, isto é, organiza, apresta, dispõe meios, pretendendo alcançar, na sociedade em que vigora, determinada finalida- 
de social. Lei é vèramente ordenação, organização social, acomodação de comportamentos, visando a finalidades de caráter eminentemente social.

De outra parte LABAND, em sua conceituação de leis formais, distinguindo entre leis pròpriamente jurídicas, leis que criam direitos e "leis administrativas", como as denomina, deita a barra muito longe, assimilando a atividade estatal, no desempenho de sua missão administrativa, à simples atividade particular, cuidando de seus próprios interêsses e gerindo sua própria fazenda. "Quando a administração, escreve LABAND, regula sua própria conduta, no interior do domínio em que sua vontade é livre e constitui lei, não invade com isto a esfera do direito, tal como um particular quando toma medidas relativas a sua casa, a sua fábrica, a sua exploração agrícola" (loc. cit. pgs. 519-520), semelhantemente a uma reunião de acionistas quando adota resoluções acêrca de assunto de seu exclusivo interêsse (loc. cit. pgs. 519-520).

É manifesto que a atividade administrativa estatal repercute na vida dos cidadãos, que integram o Estado, pois êste, em si, em certo sentido, não passa de mera abstração, não existindo senão em função dos indivíduos que formam a sociedade política. Não se poderá jamais considerar o Estado uma personalidade autônoma, com existência e interêsses próprios, independentemente das pessoas que o compõem. As atividades estatais, as atividades administrativas, são exercidas no convívio social, refletindo necessàriamente nas relações sociais, que não são outra coisa, na realidade, senão relações individuais. As regras arquitetônicas que presidem à formação dos poderes, dos corpos públicos e dos órgãos de govêrno, os princípios diretivos que regem o funcionamento dos serviços administrativos são parte integrante e capital da ordem jurídica, que pauta e dirige o comportamento dos indivíduos conglomerados em sociedade. O direito do Estado, pròpriamente dito, posto não implique necessàriamente a existência de regras de direito individual, é direito dos cidadãos, enquanto membros da coletividade. Serão regras de direito público, regras de direito administrativo, diz CARRÉ DE MALBERG (loc. cit., pg. 300), mas, certamente, são direito, afinal. 
Em suma, a célebre teoria das leis formais, tal como é apresentada, mau grado as restrições e concessões formuladas pelo próprio LABAND, seu defensor impertérrito (loc. cit., pgs. 521 e seg.; 523 e seg.), não merece, doutrinàriamente, incondicional acolhida, como também, pelo aspecto sob o qual encara o assunto, não aproveita nem soluciona a discutida questão da generalidade necessária da lei.

9. O problema específico da generalidade da lei, em nosso entendimento, data vênia, encontra solução adequada no sistema jurídico do AQUINATE. SANTO TOMÁS, que não era jurista, concebe os temas jurídicos à luz da ética em geral. Êle os considera como moralista, que é.

A generalidade da lei, para êle, decorre de sua finalidade incomutável. A lei, ordinatio rationis, visa ao bem comum. O bem comum the é finalidade e pauta. No Tratado da lei, SANTO TOMÁS, por duas vêzes, invoca a lição de ISIDORO DE SEVILHA (1a. 2ae. qu. 90, art. 2, sed. contra e 1a. 2ae., qu. 96, art. 1, sed contra): "A lei não foi escrita visando a qualquer vantagem particular, mas à utilidade comum dos cidadãos". Neste sentido, é geral. Sempre geral na finalidade que tem em mira. É editada e só se justifica enquanto atende a êsse interêsse geral, que é a ordem para o bem comum" (qu. 90, art. 3, ad resp.).

Em outra passagem, diz o ANGÉLICO DOUTOR: “A parte é ordenada com relação ao todo, como o imperfeito ao perfeito; o indivíduo humano é parte da comunidade perfeita. Assim, é necessário que a lei considere diretamente o que conduz à felicidade comum" (1a. 2ae. qu. 90, art. 3, ad. resp.). Como se vê, é sempre o bem comum que determina e orienta a lei. Ela é o espêlho, o paradigma do bem comum.

Êsse bem comum, todavia, também se realiza através de determinações particulares. Já indicamos o texto de SANTO TOMÁS. Vamos completá-lo agora. Lá se afirmava que o preceito comporta a aplicação da lei aos atos, que são por ela regulados. A regulamentação em vista do bem comum, apanágio da lei, é aplicável a fins privados. Neste sentido, são editados preceitos, relativos a certos fatos particulares. E assim é, explica SANTO TOMÁS, porque as ações (operationes), vale dizer, o operar humano se realiza por meio de fa- 
tos particulares. Êsses fatos particulares podem, entretanto, ser referidos ao bem geral, ou, melhor, podem ser apreciados em função do bem comum, não no sentido de serem classificados no mesmo gênero, ou na mesma espécie daquilo que concerne essencialmente ao bem comum, mas porque são considerados meio de contribuir para o bem comum, e neste sentido, o bem geral é denominado fim comum (qu. 90, art. 2, ad 2 um).

E, na mesma questão 90, encontramos, ainda, o seguinte lance, que é decisivo: "Em conseqüência, pois a lei só adquire plena significação por sua orientação em vista do bem comum, todo e qualquer preceito, visando a um ato particular, não adquire valor de lei senão segundo se orientar no sentido dêsse bem comum (1a. 2ae., qu. 90, art. 2, ad resp. in fine).

Assim, a decantada generalidade da lei não se encontra e se não justifica, doutrinàriamente, senão no propósito, na finalidade, que há de, necessàriamente, animar e orientar 0 preceito legal. Expressão do bem comum, a lei não pode senão ser geral, em seu propósito, generalidade decorrente de sua própria natureza. Regulando, embora, por vêzes, particulares assuntos, por meio dos quais se efetiva o bem comum, ela não se alonga da finalidade geral indeclinável, que lhe é essencial. Tudo é por ela considerado pelo prisma da utilidade geral e, neste sentido, não pode e não deve ser senão geral. É a generalidade de seus desígnios que torna a lei impessoal, isto é, sobranceira e isenta, imparcial e sagrada, inacessível a interêsses estranhos a seu ofício. Do contrário, seria violência ou arbítrio, "antes iniqüidade do que lei": magis iniquitas quam lex (1a. 2ae., qu. 90, art. 1, ad 3um).

Em suma, não só o direito, assim denominado porque é justo, diz ISIDORO DE SEVILHA, o direito, objeto da justiça, acrescenta o AQUINATE (Tratado da justiça, 2a. 2ae., qu. 57, art. 1, sed contra); mas a lei, que não é pròpriamente 0 direito, e sim a ratio iuris, a idéia exemplar, a regra ou o modêlo do direito (ibidem, ad 2 um.), a lei, fiel a sua missão de servir ao bem comum, à utilidade geral, ambos sobrepairam à preocupações pessoais e a interêsses particulares, estabelecendo entre os membros da comunidade a igualdade, forma 
da justiça (2a. 2ae., qu. 61, art. 2, ad 2um.), a harmonia e a segurança, indispensáveis à garantia da ordem e da prosperidade social.

10. À luz do exposto, tiraríamos as seguintes conclusões:

$1 .^{\circ}$ - A lei, eminentemente obra da razão, tem por função ordenar certos meios em vista de um fim (1a. 2ae., qu. 91 , art. 1, ad 3 um), que é o bem comum, isto é, a utilidade comum, na lição de ISIDORO DE SEVILHA, e, neste sentido, o bem geral, bonum commune, é chamado fim comum (qu. 90 , art. 2 , ad $2 u m$ ). Tal é o fundamento da generalidade da lei.

$2 .^{\circ}$ - Formulando grande número de regras gerais, concernentes a relações sociais que, como sói acontecer muitas vêzes, apresentam caráter de constância, regras susceptíveis de aplicação a um conjunto de pessoas e de casos, não deixa a lei, contudo, de atender a casos especiais e isolados, puramente episódicos ou momentâneos. Assim, essa generalidade de formulação habitual da lei, não lhe é necessária, nem privativa. De outro lado, a administração, o poder executivo também edita normas regulamentares de alcance geral. A generalidade se nos apresenta e se impõe, comumente, como mero processo de técnica jurídica. Conseqüentemente, a contraposição, que se pretende estabelecer, como frisa CARRÉ DE MALBERG (loc. cit., pg. 282), entre a regulamentação da lei, que procederia por via geral e a atividade administrativa, agindo por meio de determinações particulares, não se justifica, nem procede. E, no ponto, a autoridade de CARRÉ DE MALBERG se conforta com o ensinamento de MARCELO WALINE (Traité élémentaire de droit administratif, 6a. ed., 1952, pg. 6): "É falso opor o ato legislativo, necessàriamente geral, ao ato administrativo, necessàriamente particular, pois, na realidade, a generalidade de um ou a particularidade do outro são susceptíveis de tal infinidade de graus, que, insensivelmente, vai do geral ao particular".

$3 .^{\circ}$ - A distinção entre a ação legislativa, de que decorre a lei, e a atividade administrativa, acomodando meios para o exato cumprimento da lei, reside, tão sòmente, sob o aspecto em que consideramos o assunto, na hierarquia estabelecida entre as duas, subordinando-se a ação governamental ao império da lei. Ordenando a vida social e pautando o com- 
portamento de governantes e governados, só a lei é poderosa a conceder direitos e a criar obrigações. A diferença não assenta, pois, em outra coisa senão na preeminência, reconhecida à lei, naquele "poder de iniciativa", segundo CARRÉ DE MALBERG (loc. cit., pg. 341), que exclusivamente lhe pertence.

Estatuindo, muitas vêzes, por via geral, ou, em certos lances, por meio de determinações particulares e, até, personalíssimas, a lei delimita, imperiosamente, os confins da atividade construtiva da administração. Esta, subordinada à lei, procede, também, segundo as circunstâncias, por via geral ou particular. São as exigências do real, que determinam a escolha dos meios mais adequados. Mas a finalidade é sempre a mesma e geral, em seus desiígnios: o atendimento aos fins de utilidade geral, ou de bem comum, traçados na lei. 